\title{
When Passing Fails: Designing Multiple Choice Assessments to Control for False Positives
}

David N. Dubins

Leslie Dan Faculty of Pharmacy

University of Toronto

144 College St.

Toronto, Ontario, Canada

M5S 3M2

Phone 416-946-5303

Fax: 1-416-978-8511

d.dubins@utoronto.ca

Gregory M. K. Poon,

Department of Chemistry and Department of Nutrition

Brydine F. Lewis School of Nursing and Health Professionals

Georgia State University

Atlanta, GA 30303

Phone 404-413-5491

Lalitha Raman-Wilms

Leslie Dan Faculty of Pharmacy

University of Toronto

Toronto, Ontario, Canada

M5S 3M2

Phone 416-978-0616

I.raman.wilms.a@utoronto.ca

Abstract Purpose: To model the quantitative probabilistic features of multiple choice question (MCQ) style assessments, with specific focus on controlling the false positive rate ( $\alpha$ ) of wrongly passing a student, and to examine and summarize MCQ writing tips to minimize key errors in MCQ test design. Method: We generated Monte Carlo simulations and binomial probability distributions for different MCQ test structures, varying in number of questions, choices per question, and pass mark. Educated guessing and student blunder (incorrect response despite knowing the material) were modeled. Knowledge levels associated with $\alpha<5 \%$ were determined. Pass levels were then re-calculated for each test to ensure $50 \%$ and $60 \%$ levels of student knowledge, at a $<5 \%$ false positive rate. Results: Pass marks designed to detect failing levels of knowledge at $<5 \%$ error rate varied strongly with $M C Q$ test structure. Test specificity increased with test length, number of choices per question, and pass mark, revealing that pass marks should be customized to individual test structure. A discussion on appropriate MCQ structure and content is presented. Conclusion: Pass marks need to address MCQ test structure and the probabilistic nature of $\mathrm{MCQ}$ testing to accurately discriminate learner competency. 
DO NOT REFORMAT

Keywords Assessment; MCQ; Multiple Choice; False Positive

Conflicts of Interest: None.

Financial Disclosure: GMKP is supported by the National Science Foundation grant MCB 1545160. 


\section{When Passing Fails: Designing Multiple Choice Assessments to Control for False Positives}

Abstract Purpose: To model the quantitative probabilistic features of multiple choice question (MCQ) style assessments, with specific focus on controlling the false positive rate $(\alpha)$ of wrongly passing a student, and to examine and summarize MCQ writing tips to minimize key errors in MCQ test design. Methods: We generated Monte Carlo simulations and binomial probability distributions for different MCQ test structures, varying in number of questions, choices per question, and pass mark. Educated guessing and student blunder (incorrect response despite knowing the material) were modeled. Knowledge levels associated with $\alpha<5 \%$ were determined. Pass levels were then re-calculated for each test to ensure $50 \%$ and $60 \%$ levels of student knowledge, at a $<5 \%$ false positive rate. Results: Pass marks designed to detect failing levels of knowledge at $<5 \%$ error rate varied strongly with $M C Q$ test structure. Test specificity increased with test length, number of choices per question, and pass mark, revealing that pass marks should be customized to individual test structure. A discussion on appropriate MCQ structure and content is presented. Conclusion: Pass marks need to address MCQ test structure and the probabilistic nature of $M C Q$ testing to accurately discriminate learner competency.

Abbreviations MCQ: Multiple Choice Question

Keywords: assessment; MCQ; Multiple Choice; False Positive

Conflicts of Interest: None.

Financial Disclosure: GMKP is supported by the National Science Foundation grant MCB 1545160. 


\section{Introduction}

Assessing learners is a critical component of the educational process and serves many purposes. ${ }^{1}$ In the health professions, educational institutions are under increasing scrutiny to ensure that graduates achieve the required competencies upon entry to professional practice. ${ }^{2}$ Course learning objectives are increasingly tailored to fully span the cognitive, affective, and psychomotor domains. For example, expectations for students in the health professions within the cognitive domain have transcended simple recall of information, to include the analysis and application of information using case-specific clinical scenarios. ${ }^{3}$ As learning paradigms evolve, multiple choice questions (MCQs) continue to be a popular form of assessment in professional curricula. Moreover, MCQs represent a major component of competency-based board and/or licensing exams administered by health-related professions around the world. The ubiquity of MCQs reflects their many practical advantages: they can be reliable, are convenient to administer and score (especially for large numbers of students), and are amenable to quantitative post-test analysis.

Despite its usefulness, MCQ is a controversial assessment format. ${ }^{4}$ Criticisms of MCQ tests typically include: lack of familiarity with $\mathrm{MCQ}$ format; the perception of testing factual regurgitation over higherorder thinking (favoring recognition over recall), a danger of over-emphasizing pattern recognition as a diagnostic tool, the absence of active collection in clinical reasoning, issues in setting and maintaining a consistent standard, the perception of being a less professional or trivial method of testing by some, and possible difficulty with item writing.$^{5-9}$ Another specific criticism of MCQ testing as an assessment tool arises over the perceived influence of "luck" in student performance. Concepts of probability and randomness are frequently misunderstood, in part due to our desire to ascribe patterns to random events. ${ }^{10,11}$ For example, concern over the influence of luck in MCQ testing has recently resulted in an institution-wide ban of MCQ style tests in Australia's Central Queensland University. ${ }^{12}$

In the literature, advice abounds on how to appropriately write and formulate MCQs. We have summarized and organized these tips by their function in reducing error: aligning MCQs with learning outcomes (Table 1), avoiding "testwiseness," "cueing," or providing hints of the correct answer (Table 2), and ensuring question clarity (Table 3). However, qualitative strategies on wording of stem and distractors can reduce but do not fundamentally address the probabilistic effects of educated guessing and other 
acts of human nature on MCQ test-taking. Indeed, "... if teachers understood the statistics of guessing, then it is likely that multiple-choice exams would be constructed differently."13 $Q u a n t i t a t i v e ~ a p p r o a c h e s$ are needed both to unambiguously describe how probabilistic events drive MCQ test outcomes, and also to translate this knowledge to inform MCQ test design so that assessments correctly measure knowledge against preset standards of competency. To this end, statistical concepts are useful in accounting for the role of "chance" in even the best-designed questions. ${ }^{14-16}$

In statistical terms, a false positive (or more generally, Type I) error is made in testing if a subcompetent examinee passes, and a false negative (or more generally, Type II error) is made if a competent examinee fails. ${ }^{17}$ If an MCQ test has four choices (i.e., three distractors and one "key", or correct answer) per question, the probability $(p)$ of blindly guessing the correct answer is $1 / 4$ (or $p=0.25$ ). In a test with seven questions having four choices per question, the probability of a student blindly guessing all questions correctly would be $p=(0.25)^{7}=6.104 \times 10^{-5}$, or a 1:16,384 chance of scoring perfectly. While this simple calculation might initially allay concerns of a false positive for a short $\mathrm{MCQ}$ test, competency-based assessments are not aimed at testing if student knowledge is perfect. Rather, assessments must discern a continuum of knowledge level in the vicinity of the pass/fail line. Since decisions of competence are made close to this threshold, errors in both measurement and classification are possible.

Thus, optimal design of MCQ tests in the competency-based paradigm must maximize the true positive rate of awarding a passing mark to a student who has understood the material on the one hand (minimizing Type II errors, or equivalently increasing the power of the test), and maximize the true negative rate of failing a student who has an insufficient level of knowledge on the other hand (minimizing Type I error, or equivalently increasing the specificity of the test). While the risk of an under-powered MCQ test is primarily limited to the test-taker, insufficient specificity in competency-based health professions exams presents significantly broader risks to patients. In this study, we focused on the latter, and our purpose was to 1) establish a rigorous framework for understanding MCQ test structure and the probabilistic effects of test-taking behavior on knowledge detection by MCQ; and 2) translate this insight into practical guidelines for setting pass marks that appropriately control for the chances of a false positive error. 


\section{Methods}

To sample the probabilistic nature of MCQ tests, we first performed Monte Carlo simulations of virtual MCQ tests, and then deduced exact probabilities from binomial probability distribution functions. Simulated MCQ tests varied in length from two to three-hundred total questions. The number of choices per question was three, four, or five, based on their frequent use in practice.

\section{Monte Carlo Simulation.}

Monte Carlo simulations were carried out in R-Studio (version 0.98.501), on top of the R-Project platform (version 2.15.3) by the primary author (DD). The algorithm involved first setting up a random answer guide for a given test structure (defined by \# questions, \# choices/question). No actual question stems or options were worded. The program then generated virtual "students" with increasing levels of knowledge for each test. Students provided the corresponding number of correct answers for their level of knowledge, and then randomly guessed answers for the remaining questions. For example, a 10question, five choices/question test was set up with a random answer guide: 1:A, 2:B, 3:E, 4:D, 5:D, 6:A, 7:C, 8:A, 9:A, 10:D. To simulate a student with $40 \%$ knowledge (4/10 questions), the student's test answers matched four questions on the answer guide: (e.g. 1:A, 2:B, 3:E, 4:D), and randomly sampled the remaining questions from options $A, B, C, D$, and $E$, at an equal probability of selecting each choice. Tests were then graded against the answer guide, and their mark frequencies were recorded. For each simulation, 100,000 students were used per level of knowledge if the total number of questions on the test was less than 100, and 10,000 students were used for larger tests (total \# questions $\geq 100$ ). These simulation sizes were selected as a practical balance of statistical reliability and computer simulation time.

\section{Educated guessing.}

Students who do not know the answer to a question may nonetheless be able to eliminate an implausible or poorly-designed distractor, or perhaps recall enough information about the distractor to eliminate it as a viable alternative. This increases the chance of a student arriving at the correct answer based on partial knowledge. ${ }^{14}$ To simulate educated guessing, each "unknown" question was given an equal probability of eliminating 0 to [\# choices/question - 2] distractors. Although eliminating [\#choices/question - 1] options would be equivalent to knowing the correct answer, educated guessing at the correct response is not the same as a priori knowledge of the correct option: the former is 
probabilistic, the latter is not. This is an intrinsic limitation of MCQ-style questions, but arguably has a useful clinical analogue - ruling out is an integral feature of differential diagnoses.

\section{Student Blunder.}

Defined as the occurrence that the student scored incorrectly on a question for which they understood the material and should have otherwise scored correctly, student blunder can arise for a variety of reasons, such as: misreading the question, misinterpreting a poorly worded question, improperly bubbling the answer sheet, test fatigue, stress, health, and environmental factors. To probe the effect of student blunder on the specificity of the test, we set the student blunder rate $(\beta)$ at 0 or $5 \%$. It should be noted that a student blunder rate of $5 \%$ should be considered an approximate, if not arbitrary estimate. One recent study showed refinement of poorly worded questions that would lead to student blunder in an MCQ bank reduced test flaws by $11 \%{ }^{8}$ With properly worded questions, student blunder rate could be much lower. As a first approximation, the magnitude of improperly bubbling answers can be estimated by looking at errors made by students bubbling in their student identification numbers (approximately $1-2 \%$ of scantron sheets collected for laboratory quizzes). This estimate was rounded up to $5 \%$ to account for a student misreading or second-guessing questions. Regardless of the $5 \%$ estimate we selected, other magnitudes may be incorporated into the model, and evaluated as such.

\section{Binomial Probability Distribution calculations.}

To assess the validity of the Monte Carlo simulations, analytical relations were derived from binomial probability equations for each MCQ test, in both R-Project and Microsoft Visual Basic for Applications 7.0 in Microsoft Excel 2010, by the primary author (DD). Copies of the programs may be obtained through the primary author.

Although there are typically more than two options in each MCQ, there are only two effective outcomes: the student answers correctly, or the student answers incorrectly. Following the logic of a Bernoulli trial, if we assign the random variable $X$ to the outcome of each $M C Q$, and an independent probability $p$ for answering each question correctly, the binomial theorem gives the exact probability of a series of independent events as follows:

$$
P(X=x)=\left(\begin{array}{l}
q \\
x
\end{array}\right) p^{x}(1-p)^{q-x} ; \text { where }\left(\begin{array}{l}
q \\
x
\end{array}\right)=\frac{q !}{x !(q-x) !}
$$


Applied to our model of a multiple choice test, $x$ is the total mark a student obtains on the MCQ test, $q$ is the total number of questions on the MCQ test, and $p$ is the probability of a student guessing a single question correctly ( $p=1 /$ \#choices per question). In Equation (1), $\mathrm{P}$ represents the probability of obtaining a total mark of $x$, resulting from guessing $x$ questions correctly out of $q$ total questions.

Equation (1) describes the expected mark distribution for a student who guesses at every MCQ blindly in a test, by solving for the probabilities for marks $x=0,1, \ldots, q$. However, student knowledge alters this equation, since a student "knowing" the answer to a question a priori eliminates the necessity of guessing. We can modify Equation (1) to "subtract off" questions handled by student knowledge, to derive the probability for each mark for students guessing at the remaining questions:

$$
P(X=x)=\left\{\begin{array}{c}
0, x<k \\
\left(\begin{array}{c}
q-k \\
x-k
\end{array}\right) p^{x-k}(1-p)^{q-x}, x \geq k
\end{array}\right.
$$

where $x$ is the total mark the student obtains (including known questions, and questions guessed correctly), and $k$ is the total number of questions known by the student. To incorporate a student blunder rate $(\beta)$ into the model, the following equation was derived:

$$
P(\mathrm{X}=x)=\sum_{i=\max (0, x-q+k)}^{\min (k, x)}\left[\left(\begin{array}{c}
k \\
i
\end{array}\right)(1-\beta)^{i}(\beta)^{k-i} \cdot\left(\begin{array}{c}
q-k \\
x-i
\end{array}\right)(p)^{x-i}(1-p)^{q-k-x+i}\right]
$$

Equation (3) simplifies to Equation (2), when $\beta$ is set to 0 , enabling it to be used in programming without having to switch between different scenarios. This is the equation that was used to model how the manipulation of key factors in the construction of MCQ tests affects their outcomes. The key factors we chose to examine were: changing the number of choices per question, educated guessing, student blunder, changing the number of questions, and setting the pass mark.

We assessed the specificity of a MCQ test by answering the question: what level of knowledge does the $\mathrm{MCQ}$ test reliably fail? We defined $\mathrm{LK}_{\mathrm{a}<5 \%}$ as our principle measure: the level of knowledge (or, the number of questions a student knows the answers to) resulting in up to a $5 \%$ false-positive rate (specificity). Students with levels of knowledge above the $\mathrm{LK}_{\mathrm{a}<5 \%}$ (but below the pass mark) would then have a higher than $5 \%$ chance of passing the test. We used hypothetical tests ranging from 2 to 300 questions, with three to five choices per question. We then estimated the pass marks required to detect $50 \%$ and $60 \%$ knowledge for various MCQ test structures, with $\leq 5 \%$ of a false positive. 


\section{Results}

The results for the estimation of $\mathrm{LK}_{\mathrm{\alpha}<5 \%}$ for MCQ tests of 2 to 300 questions, ranging from three to five choices per question are presented in Table 4. This provides a useful tool allowing MCQ test designers to see what levels of knowledge their current MCQ tests can successfully identify a failing level of competence, at an error rate of $5 \%$. An interesting feature of these results is the lack of ability of shorter MCQ tests to fail a student having no knowledge of the questions, reflected in absence of values reported in the table. Our estimation of pass marks that would be expected to have a $95 \%$ chance of failing a student who has less than $50 \%$ and $60 \%$ levels of knowledge, respectively, are presented in Table 5, providing conservative ranges for MCQ test designers to consider while setting standards.

To illustrate our probabilistic approach to MCQ analysis, we examined a current pharmaceutics quiz administered to students, consisting of 7 questions, with 4 choices/question, and a pass mark of $60 \%$. Both the Monte Carlo simulations and binomial probability distribution (using Equation 2) iterated through all possible levels of student knowledge, yielding $\mathrm{LK}_{\mathrm{a}<5 \%}=1$ question for this test, meaning that this specific test will pass a student who knows 1 (or less) out of 7 questions, less than $5 \%$ of the time. Students who have a higher (but still failing) level of knowledge have $a \geq 5 \%$ chance of passing. These results do not include the effects of educated guessing or student blunder, and can be thought of as a best-case scenario for the test, with each question appropriately formulated with perfectly balanced distractors. Thus, although the quiz pass mark satisfies the departmentally-set pass mark of $60 \%$, it presents a significant probability of passing students with (failing) levels of knowledge who only know the answers to 2, 3, or 4 questions. In fact, if a student is able to answer 4 questions correctly (still a failing level), they have a $57.8 \%$ chance of passing the test (using Equation 2). If the effects of student blunder and educated guessing are incorporated into the model (Equation 3), then the chances of a student passing the test not knowing the answers to any questions and randomly guessing are $6.3 \%$ (data not shown). Consequently, the $\mathrm{LK}_{\mathrm{a}<5 \%}$ is not estimable for a 7-question MCQ with 4 choices per question, when student blunder and educated guessing are included in the model, highlighting that the test structure does not permit a $<5 \%$ chance of failing a student.

Changing the number of choices per question increases specificity of an MCQ test. 
Increasing the number of choices per question, provided they are good distractors, reduces the probability of a student blindly guessing the correct answer. One of the challenges in MCQ test design is the formulation of homogeneously plausible distractors. The payoff in writing those extra distractors is that it dramatically increases the $\mathrm{LK}_{\alpha<5 \%}$ for longer MCQ tests. Due to the discrete nature of $M C Q$ test responses, there are instances where increasing the number of choices does not affect the $\mathrm{LK}_{\alpha<5 \%}$ of shorter MCQ tests (<20 questions). For our 7-question MCQ example, if the 4 choices/question test is compared with 5 choices/question, the $\mathrm{LK}_{\mathrm{a}<5 \%}$ is unchanged at 1 question, illustrating that this effect is not necessarily seen with fewer numbers of questions on the test. It is difficult to completely generalize the effect of changing the number of questions since it depends on other factors; however, writing more options per question makes the assessment tool more efficient, and is a good idea for MCQ tests aimed at assessing competence.

Educated guessing significantly reduces $M C Q$ test specificity.

If a student does not know the answer to a question, eliminating distractors recognized as false, increases the probability of guessing the correct answer. We modeled this effect by eliminating 0 to [\#choices-2] distractors for unknown questions, with an equal probability assigned to each level of item reduction happening. Educated guessing therefore had the functional effect of increasing the average probability of guessing the question correctly, and is conceptually equivalent to the eliminated distractors never having been present in the first place. When educated guessing was simulated in a test with 4 choices/question, the resultant probability of guessing a question correctly was increased from 0.25 to the average probability of guessing from 4,3 , and 2 choices (average[0.25,0.333,0.5] $=0.36$ ). Similarly, educated guessing with 5 choices/question resulted in 0.32 (average[0.2,0.25,0.33,0.5] = 0.32), compared with 0.2 for blind guessing. We found that educated guessing had a profound influence on the specificity of each test: $\mathrm{LK}_{\alpha<5 \%}$ dropped from 1 question to "-“ (not reported), meaning that a student with zero level of knowledge has a $>5 \%$ chance of passing this test if they were able to eliminate distractors at a rate similar to this model. In other words, educated guessing greatly increased the chances of passing, and if it is to be taken into account, resulted in a substantial advantage for the student. Consequently, higher pass marks should be considered if educational guessing is thought of as a poor demonstration of knowledge and/or competence. 
Student Blunder Rate can increase MCQ test specificity.

The inclusion of a student blunder rate $(\beta=5 \%)$, independent of educated guessing, resulted in a drop in student performance. Regardless of the number of questions, at a $100 \%$ level of student knowledge, the average performance dropped by the same magnitude of the student blunder rate, to $95 \%$ (data not shown). This effect alone was not sufficient to change the $\mathrm{LK}_{\mathrm{a}<5 \%}$ of our 7-question $\mathrm{MCQ}$ test (data not shown). For tests with more than 2 questions, however, introducing a student blunder rate alone to the model reduced the false positive rate of the test. While our simulations have the capability of testing student blunder rate independently of educated guessing, we chose to combine these effects in our model. Mathematically this effect plays in favour of test specificity; however, student blunder on a poorlyworded question is not reflective of the student's competency, and contributes towards the Type II error. In short, it is important for the test author to write clear, internally consistent questions, and make every attempt to minimize student blunder rate, since this effect can make a competent student fail an assessment. Tips are provided specifically in Table 3 to promote clarity, and minimize comprehension errors. Our projected blunder rate of $5 \%$ did not overshadow the effect of educated guessing.

Increasing the Number of Questions can increase test specificity.

Intuitively, test length should be sufficient to ensure that students are not simply guessing their way to a passing grade. ${ }^{18}$ Our analysis shows that the total number of questions strongly influences the specificity of the MCQ test, although in both binomial probability distributions and Monte Carlo simulations, increasing the number of questions showed diminishing returns in some cases. Particularly with shorter tests, the discrete nature of mark distributions and the position of the pass mark result in highly variable trends in $\mathrm{LK}_{\mathrm{a}<5 \%}$. Table 4 and Table 5 can be used as a decision tool for deciding the minimum number of questions required to reject a failing level of competence.

\section{Raising the Pass Mark increases MCQ test specificity.}

While determination of the test specificities at pass marks of $50 \%$ and $60 \%$ provided mechanistic insights into MCQ test dynamics, the more practically relevant question is: "what pass marks should be set to detect a student level of knowledge of at least $50 \%$ and $60 \%$, respectively?" Table 5 shows that as the number of questions increases, the pass mark required to detect a level of knowledge decreases. Thus, longer MCQ tests increase our confidence in assessing a specified level of knowledge. For 
example, an MCQ test with 200 questions required a 2 to $2.5 \%$ lower pass mark compared to a test with 100 questions, depending on the level of knowledge desired, and the model used. Setting an appropriate pass mark is extremely important in assessing competence, with negative consequences associated with it being too high or too low. Our results show that typical pass marks of $50 \%$ and even $60 \%$ are not measuring levels of knowledge even close to those pass marks, illuminating a concerning characteristic of MCQs.

A summary of the effects of changing each explored structural element is presented in Table 6 . The combined effects of educated guessing and student blunder mainly resulted in an increase in the required pass mark, although in some cases (testing a 60\% level of student knowledge), the effects resulted in no change (e.g. 3 choices/question with 70 questions). Thus, the interplay of these two factors did not always result in the same overall effect.

\section{Discussion}

MCQ tests have a colorful and interesting history, beginning with a wooden apparatus developed by Yerkes in the early 1900s to explore intelligence of monkeys. ${ }^{19}$ There has been much development of MCQ tests and pass-mark analysis, particularly in the field of psychology. ${ }^{20}$ Many strategies have been advanced for designing MCQs and setting the passing standard; however, relatively few take the probabilistic nature of the MCQ test taking into account. ${ }^{21,22}$ Such approaches typically involve strategies for penalizing wrong answers. ${ }^{21}$ In Bandaranayake's ${ }^{17}$ guide on setting standards for MCQ testing, he concluded that it would be better to specify the performance standard, and develop the test to fit that standard rather than applying a standard-setting procedure to an existing test. Controlling for the false positive rate allows the MCQ test designer to do just that - decide what level of competence a candidate should have, rigorously account for the statistics of $M C Q$, and then design the test accordingly. For instance, after designing a blueprint for an MCQ bank, we might set competency at $50 \%$ knowledge level, and decide that our test should have less than a $5 \%$ chance of a false positive. Table 4 reveals that neither $50 \%$ nor $60 \%$ pass marks reliably detect students who have a $50 \%$ knowledge level even at 300 questions, and the most reasonable strategy to accomplish this, rather than creating more questions for the student, or more than five options per question, is to increase the pass mark. In Table 5, we find that a properly designed 200-question MCQ test with 4 choices/question, should have a pass mark in the 
vicinity of 66.5 to $70.5 \%$ in order to ensure that a student with less than $50 \%$ knowledge would have no higher than a $5 \%$ chance of passing the test. Such a test would have a much higher ability to discern a lack of competence, by accounting for correct answers due to guessing. Once the pass mark is decided, each MCQ should be reviewed by eyes other than the author's, following the MCQ-writing guidelines presented in Table 1 to ensure alignment with course objectives; Table 2 to minimize the effect of cueing (thus limiting the effects of educated guessing); and Table 3 to ensure questions are clear (thus limiting the effects of student blunder). These tables are provided to improve the ability of the test to measure competence, and to minimize student and instructor error due to improper question structure and wording.

Our probabilistic approach to MCQ test design challenges the traditional paradigm of standard limit setting, ${ }^{17}$ and provides a more rigorous basis for standard setting than calculating a "total ignorance" score equivalent to the probability of guessing a single MCQ correctly. Use of probability distributions accounts for and acknowledges expected effects due to chance. In addition, this method is fairer than strategies such as negative marking, which encourage students to not even try a question when they are not sure, second-guess themselves on questions they know, and fail to control for students who obtained a high score on the test by guessing well. ${ }^{15,23,24}$ To illustrate the last point, a student who guesses extremely well and is adept at finding question cues could potentially score perfect, and receive no penalty whatsoever in these mark deduction schemes. Yet another interesting strategy devised is to award (1/\#choices) mark for leaving a question blank, with explicitly communicated intentions to discourage random guessing. ${ }^{13}$ There are many strategies to determining test-centered and examineecentered standards. Any of these strategies could be used to determine the minimal level of competence, and then Table 5 could be used to properly account for chance.

One of the key observations in our probabilistic analysis of MCQ testing is the strong effect of the number of choices per question on controlling the false positive rate. Specifically, increasing question complexity from three to five choices per question reduces $\mathrm{LK}_{\alpha<5 \%}($ Table 4$)$ and the pass mark required to detect a given level of knowledge (Table 5). This insight is significant in light of proposals to reduce the number of choices from as many as five per question down to three per question. Lowering item complexity finds rationale in empirical evidence showing that item difficulty and discrimination were not 
significantly compromised when eliminating from five or four choices down to three choices per question. $^{22}$ However, approaching this problem with our most conservative model (Equation 2), a 300question MCQ test with three choices per question could not reliably fail a student having a level of knowledge as low as 57 questions, or $19 \%\left(\mathrm{LK}_{\mathrm{a}<5 \%}=56\right.$ questions) when the pass mark is $50 \%$, and as low as 103 questions, or $34.3 \%$ ( $\left(\mathrm{KK}_{\mathrm{a}<5 \%}=104\right.$ questions) when the pass mark is $60 \%$. To ensure at least $50 \%$ knowledge, a 300 -question, three options per question test would require a pass mark greater than $70 \%$. In terms of the false positive rate, a 300-question test with three choices per question has a $\mathrm{LK}_{\mathrm{a}<5 \%}$ proportionally similar to a 50-question test having four choices per question $\left(\mathrm{LK}_{\alpha<5 \%}=17 / 50\right.$ questions $=$ $34 \%)$, and a 30-question test having five choices per question $\left(\operatorname{LK}_{\alpha<5 \%}=10 / 30\right.$ questions $\left.=33.3 \%\right)$. Thus, a reduction in options significantly reduces test specificity. Although fewer choices per question alleviates the need for plausible alternatives, more questions are required to maintain an equivalent level of specificity.

While increasing complexity has a consistently beneficial effect on reducing the false positive rate for long tests, shorter tests do not enjoy this benefit. A 10-question MCQ test with a 50\% pass mark does not reliably detect a failing level of knowledge, regardless of the number of choices per question we examined. Although this result shows poor specificity for tests with $<20$ questions, short MCQ tests find much value in low-stakes assessments. Provided their relative contributions to overall student grade are quantitatively minor, short MCQ tests have important niches during educational encounters. When administered at the beginning of a class, they can encourage students to prepare for class, to pay close attention when administered during or after a class, and in general, they can help consolidate knowledge, highlighting salient points. More generally, our results are not aimed at prescribing or cautioning an exact MCQ structure, but rather at equipping the reader with the understanding of $M C Q$ test structure attributes on specificity.

In our current models, we limited our analysis to understand MCQ tests with independent and equally weighted questions using the binomial distribution. In addition, we limited our simulations to questions and results having an equal number of choices per question, and assumed an even probability of eliminating distractors in educated guessing. More complex test structures could be modeled by incorporating a weighting scheme in the Monte Carlo simulations. In Table 5, we set the student blunder 
error at $5 \%$. With smaller test sizes, student blunder balanced the effects of educated guessing, and with larger test sizes (>10 questions) the effects of educated guessing predominated, requiring higher pass marks. The model could also be employed to control for the false negative rate of MCQ tests. Setting a pass mark too high increases the probability of failing competent students who should otherwise pass. Our focus on controlling for the false positive rate reflects the broader importance, in our view, of assessments as tools for discerning candidates with failing levels of required knowledge.

\section{Putting theory into practice: a worked example.}

To illustrate how educators can directly translate this information in their own teaching contexts, suppose an instructor wishes to optimize an MCQ exam to account for probabilistic variability in MCQ test taking. Starting with an existing test structure of 80 MCQs with 4 choices per question, and a pass mark of $50 \%$, we use Table 4 to understand the level of knowledge the current test reliably fails. Given that educated guessing occurs, and a student blunder rate of $5 \%$, we find from Table 4 that $\mathrm{LK}_{\alpha<5 \%}$ is 6 questions (out of 80 ). This means that students knowing more than 6 out of 80 questions (or $7.5 \%$ ) have a greater than $5 \%$ chance of passing the existing test structure. To improve the specificity of this exam, we use Table 5 to find a new test structure that would pass no more than $5 \%$ of students lacking a minimum knowledge level of $50 \%$. Using the same assumptions as before (educated guessing, and a student blunder rate of $5 \%$ ), we find from Table 5 that a pass mark of $73.8 \%$ will result in less than a $5 \%$ chance of a student knowing less than $50 \%$ of the questions (or 59 out of 80 questions) passing. Alternately, we can select a different MCQ test structure (e.g. using more choices per question, and/or adding more questions) using Table 5, and set the pass mark accordingly. For instance, the instructor may choose to test a $50 \%$ level of knowledge, using the same number of MCQs, but with 5 options per question. This would lower the pass mark to $71.3 \%$. The instructor may choose to ignore the effects of student blunder and educated guessing from the model, on the premise that that eliminating a wrong answer is a credible display of partial knowledge in their specific teaching context. The pass mark for an 80-question MCQ test with 5 options per question would then be reduced to $66.3 \%$. Finally, the instructor can use Tables 1 to 3 to review, critique, improve, and refresh their current MCQ bank. This would result in better alignment of MCQs with course goals and objectives, less cueing, and fewer errors made by students due to poor comprehension rather than a lack of knowledge. 


\section{Conclusion}

The primary contribution of this work is three fold: we pool advice and tips in designing better MCQs, we derive and present a more realistic statistical model for the ability of an MCQ test to assess student competence, and finally, we present tables to assess the ability of current MCQ tests to evaluate student knowledge, and to provide pass marks which would be expected to have less than $5 \%$ error rates demonstrating at least $50 \%$ and $60 \%$ levels of knowledge. As our data show, a test that also accounts for the inherently probabilistic nature of MCQ test taking can objectively be devised to have less than a $5 \%$ chance of passing a student with a failing level of knowledge. Information shared in this manuscript will enable instructors to design effective MCQs that can ensure that students are tested to demonstrate the required level of competence in any area. Now, instructors can design MCQ tests differently, by better understanding and taking into account the statistics of guessing. ${ }^{13}$ 


\section{Glossary Terms}

False positive rate. The fraction of candidates without the required level of knowledge who would score a passing mark in a test. Symbol $\alpha$.

False negative rate. The fraction of candidates with the required level of knowledge who would fail a test. Specificity. The statistical ability of a test to fail candidates without the required level of knowledge; it is the "true negative" rate $(1-$ false negative rate).

Power. The statistical ability of a test to pass candidates with the required level of knowledge; it is the "true positive" rate (1- false positive rate).

Educated guessing. Rational elimination of distractors in a multiple choice question, thus increasing the probability of choosing the correct response based on only partial knowledge.

Student blunder. The occurrence that the student scored incorrectly on a question for which they understood the material, and should have otherwise scored correctly. 


\section{References}

1. Eva KW. The value of paradoxical tensions in medical education research. Med Educ. 2010;44(1):34.

2. Keating J, Dalton M, Megan D. Assessment in clinical education. In: Delany C, Molloy E, eds. Clinical education in the health professions. Sydney ; New York: Churchill Livingstone/Elsevier; 2009:xviii, $193 \mathrm{p}$.

3. Bloom BS, Englehart MD, Furst EJ, Hill WH, Krathwohl DR. Taxonomy of educational objectives: The classification of educational goals. Handbook I: Cognitive domain. 1st ed. New York,: David McKay Company; 1956.

4. Shumway JM, Harden RM. AMEE Guide No. 25: The assessment of learning outcomes for the competent and reflective physician. Med Teach. 2003;25(6):569-584.

5. Collins J. Writing Multiple-Choice Questions for Continuing Medical Education Activities and SelfAssessment Modules. RadioGraphics. 2006;26(2):543-551.

6. DiSantis DJ, Ayoob AR, Williams LE. Journal Club: Prevalence of flawed multiple-choice questions in continuing medical education activities of major radiology journals. AJR Am J Roentgenol. 2015;204(4):698-702.

7. Freiwald T, Salimi M, Khaljani E, Harendza S. Pattern recognition as a concept for multiple-choice questions in a national licensing exam. BMC Med Educ. 2014;14:232.

8. Khan HF, Danish KF, Awan AS, Anwar M. Identification of technical item flaws leads to improvement of the quality of single best Multiple Choice Questions. Pakistan Journal of Medical Sciences. 2013;29(3):715-718.

9. McCoubrie P. Improving the fairness of multiple-choice questions: a literature review. Med Teach. 2004;26(8):709-712.

10. Mlodinow L. The Drunkard's walk : how randomness rules our lives. 1st Vintage Books ed. New York: Vintage Books; 2009.

11. Taleb NN. Fooled by Randomness: The Hidden Role of Chance in the Markets and in Life. New York: Vintage Books; 2001.

12. CQ University scraps multiple choice exams in an Australian first. Vol 2015: ABC News; 2014. 
13. Campbell ML. Multiple-Choice Exams and Guessing: Results from a One-Year Study of General Chemistry Tests Designed To Discourage Guessing. J Chem Educ. 2015;92(7):1194-1200.

14. Burton RF. Quantifying the Effects of Chance in Multiple Choice and True/False Tests: Question selection and guessing of answers. Assess Eval High Educ. 2001;26(1):41-50.

15. Burton RF. Misinformation, partial knowledge and guessing in true/false tests. Med Educ. 2002;36(9):805-811 .

16. Burton RF, Miller DJ. Statistical Modelling of Multiple-choice and True/False Tests: ways of considering, and of reducing, the uncertainties attributable to guessing. Assess Eval High Educ. 1999;24(4):399-411.

17. Bandaranayake RC. Setting and maintaining standards in multiple choice examinations: AMEE Guide No. 37. Med Teach. 2008;30(9-10):836-845.

18. Burton RF. Sampling knowledge and understanding: how long should a test be? Assess Eval High Educ. 2006;31(5):569-582.

19. Trewin SA. Robert Yerkes' multiple-choice apparatus, 1913-1939. Am J Psychol. 2007;120(4):645660.

20. Standards for Educational and Psychological Testing: American Educational Research Association, American Psychological Association, National Council on Measurement in Education; 2014.

21. Scharf EM, Baldwin LP. Assessing multiple choice question (MCQ) tests - a mathematical perspective. Active Learning in Higher Education. 2007;8(1):31-47.

22. Rodriguez MC. Three Options Are Optimal for Multiple-Choice Items: A Meta-Analysis of 80 Years of Research. Educational Measurement: Issues and Practice. 2005;24(2):3-13.

23. No more negative marking in multiple choice questions. Vol 2015: Ghent University; 2013.

24. Burton RF. Multiple choice and true/false tests: reliability measures and some implications of negative marking. Assess Eval High Educ. 2004;29(5):585-595.

25. French M, Neumann M. Large Classroom Teaching: Practical tips for designing \& implementing multiple choice tests.: Centre for Teaching Support \& Innovation, University of Toronto.

26. Wood T, Cole G, Curtis L. Developing Multiple-Choice Questions for the RCPSC Certification Examinations: Royal College of Physicians and Surgeons of Canada Office of Education; 2004. 
27. Sadaf S, Khan S, Ali SK. Tips for developing a valid and reliable bank of multiple choice questions (MCQs). Educ Health (Abingdon). 2012;25(3):195-197.

28. Frank I, Devitt P, Blackmore D, Bouchard C. Guidelines for the Development of Multiple-Choice Questions: Medical Council of Canada; 2010.

29. Case SM, Swanson DB. Constructing Written Test Questions For the Basic and Clinical Sciences, Third Edition (Revised). Philadelphia, PA: National Board of Medical Examiners; 2002.

30. Liu N, Li XW, Zhou MW, Biering-Sorensen F. The influence of question design on the response to self-assessment in www.elearnSCI.org: a submodule pilot study. Spinal Cord. 2015;53(8):604-607. 
Table 1. Tips to align questions with course goals and objectives (content validity)

- Base questions on important content and skills/learning outcomes. ${ }^{8,25,5}$

- Questions should be written at an appropriate difficulty level (appropriate does not necessarily mean difficult). Avoid irrelevant difficulty.

- Include questions that test multiple levels of Bloom's Taxonomy (remembering, understanding, applying, analyzing, evaluating). ${ }^{25}$

- Develop an examination blueprint to ensure all concepts that are considered essential and important are given fair and balanced representation on the examination. This will also help overcome writer's block. ${ }^{9,27}$

- Involve curriculum planners, content experts, course coordinators, and medical educators in developing the examination blueprint and bank. ${ }^{27}$

- Avoid testing trivial and non-essential information (factoids). ${ }^{26,28,29}$

- Questions should test the application of clinical knowledge rather than the recall of information, making the question clinically relevant and valid to the candidates. ${ }^{26,27,28,29}$

- Define and track question attributes in the bank of questions. ${ }^{27,28}$

- Perform a post-hoc statistical analysis across more than one assessment. Use the results to modify/refine/correct/remove questions. Each question should be critically reviewed before reuse. ${ }^{9,27}$ 
Table 2. Guidelines to avoid giving away the right answer/"cueing" (Type I error reduction)

\begin{tabular}{|c|c|c|}
\hline General Tips & The Stem & The Options/Alternatives \\
\hline $\begin{array}{l}\text { - Create at least } \\
\text { two versions of } \\
\text { the test, to } \\
\text { impede cheating } \\
\text { during the test. } \\
\text { - Vary MCQ test } \\
\text { questions and } \\
\text { answers from } \\
\text { year to year, to } \\
\text { avoid } \\
\text { transmission of } \\
\text { questions } \\
\text { between student } \\
\text { cohorts. }\end{array}$ & $\begin{array}{l}\text { - Make sure } \\
\text { questions are } \\
\text { independent - } \\
\text { avoid giving the } \\
\text { answer to one stem } \\
\text { in another } \\
\text { stem. }{ }^{25,26} \\
\text { - Avoid making } \\
\text { the answer to one } \\
\text { stem required } \\
\text { knowledge for a } \\
\text { subsequent stem. } \\
\text { - Avoid } \\
\text { grammatical and } \\
\text { syntactical clues in } \\
\text { the stem (e.g. } \\
\text { ending a stem with } \\
\text { "an..." vs. "a...") } \\
25,5\end{array}$ & 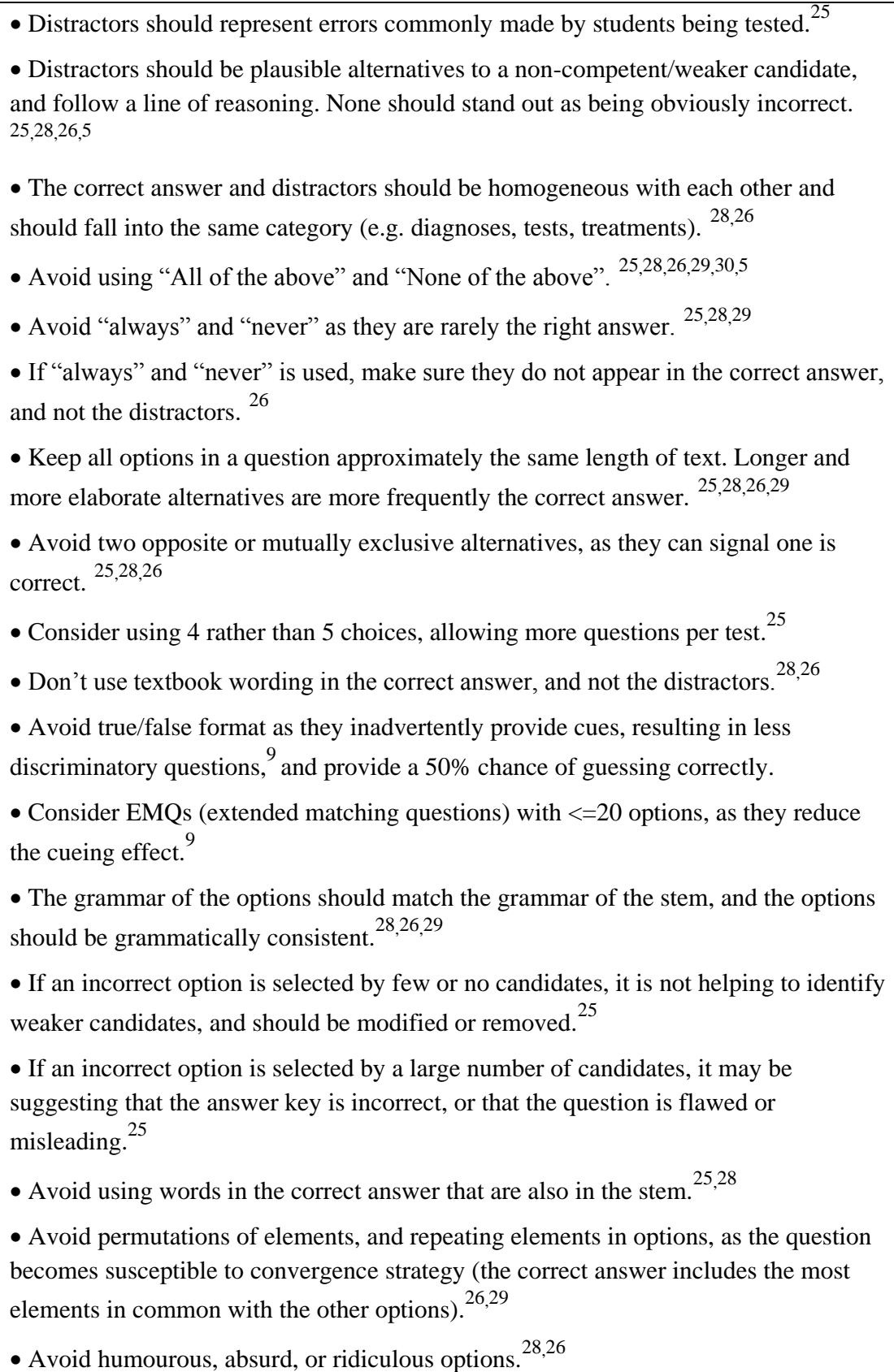 \\
\hline
\end{tabular}


Table 3. Guidelines to promote clarity, and minimize comprehension errors (Type II error reduction)

\begin{tabular}{|c|c|c|}
\hline General Tips & Stem & Options/Alternatives \\
\hline $\begin{array}{l}\text { - Provide example MCQs (multiple choice questions) for } \\
\text { students ahead of time. }{ }^{25} \\
\text { - Post tips on how to write MCQs. }{ }^{25} \\
\text { - Present a single, definite question to be answered by only } \\
\text { one option. }{ }^{25,28,29} \\
\text { - Keep vocabulary simple/appropriate for the group being } \\
\text { tested. Even wrong answers should contain words familiar to } \\
\text { the student. } \\
\text { - Avoi, } \\
\text { used, emphasid negatives (e.g. "except"), and double negatives. If } \\
\text { - Avoid using overly tricky/complex questions. The goal is } \\
\text { to test the competency of a candidate, not trick them. }{ }^{28} \\
\text { - Instruct students to select the best answer. }{ }^{25,26} \\
\text { - Avoid vague/ambiguous/imprecise terms (e.g. frequently, } \\
\text { may, usually, sometimes, seldom, often). }{ }^{92,26,29,5} \\
\text { - Proofread the test several times. }{ }^{25,5} \\
\text { - Have colleagues proofread the test. }{ }^{25,26,27,8,5} \\
\text { - Consider a 2-stage review for exams once generated - } \\
\text { peer/departmental review, followed by a multidisciplinary } \\
\text { review. }{ }^{27} \\
\text { - Provide all involved faculty members with basic training in } \\
\text { MCQ, conducted by experts in medical education. }{ }^{27,8} \\
\text { - Grammatical errors/flaws accidentally invalidate the } \\
\text { question and/or potential alternatives. }{ }^{5} \\
\text { - Avoid using acronyms. If used, acronyms should follow } \\
\text { full spelling of terms. e.g. magnetic resonance imaging } \\
\text { (MRI). }{ }^{28,26,5} \\
\text { - Refer to a drug using the generic name. If clarification is } \\
\text { warranted, use the trade name in brackets. }{ }^{28} \\
\text { - Avoid verbosity (extra words), window dressing } \\
\text { (extraneous material), and red herrings (information designed } \\
\text { to mislead the examinee). }{ }^{28,5}\end{array}$ & $\begin{array}{l}\text { - Make stems clear, } \\
\text { concise, and only } \\
\text { contain relevant } \\
\text { information. }{ }^{25,28,26,8} \\
\text { - Phrase the stem as a } \\
\text { question rather than an } \\
\text { incomplete } \\
\text { statement. } \\
\text { - Th,26 } \\
\text { - The stem should } \\
\text { contain all of the } \\
\text { information that is } \\
\text { necessary to answer the } \\
\text { question. }{ }^{28,26,5} \\
\text { - The stem should } \\
\text { provide enough detail } \\
\text { for a competent } \\
\text { candidate to answer it } \\
\text { without having to read } \\
\text { any of the options. }{ }^{28,26} \\
\text { - The stem should } \\
\text { contain a clear lead-in } \\
\text { question for the } \\
\text { options. }{ }^{28,26} \\
\text { - The stem should ask } \\
\text { for the correct answer, } \\
\text { not the wrong answer. }\end{array}$ & $\begin{array}{l}\text { - The correct answer } \\
\text { should be defensibly } \\
\text { better than the other } \\
\text { options, and should be } \\
\text { "clearly correct". } \\
\text { - Have one or more } \\
\text { colleagues confirm the } \\
\text { best answer. } \\
\text { - } 25, \\
\text { - Options should be as } \\
\text { brief as possible. Move } \\
\text { repeated words in each } \\
\text { option to the stem. } \\
\text { - Avoid overlapping } \\
\text { content in response } \\
\text { options - try to make } \\
\text { options independent. } \\
\text { - When numeric options } \\
\text { are used, options should } \\
\text { be listed in numeric (or } \\
\text { chronologic) order, in a } \\
\text { single format. } \\
\text { - Keep the number of } \\
\text { choices consistent } \\
\text { across the test and } \\
\text { course. } \\
\text { - Keep all options on } \\
\text { the same page. } \\
\text { - The position of the } \\
\text { correct answer should } \\
\text { be varied (e.g. not all } \\
\text { correct answers are } \\
\text { option "c"). }\end{array}$ \\
\hline
\end{tabular}


Table 4. $\mathrm{LK}_{\alpha<5 \%}$ values (Level of Knowledge at a Type I error rate of 5\%) presented as number of questions known, for multiple choice question tests ranging in \#questions from 2 to 300 . Students having levels of knowledge above these values (but below the pass mark) have a $\geq 5 \%$ chance of passing, resulting in a false positive. Values were computed from binomial distributions (Equation 3) or Monte Carlo simulations (boldface text) when limits of 64-bit computer arithmetic were reached. Table values are presented as ( $\beta=0 \%$; no educated guessing / $\beta=5 \%$; with educated guessing). Educated guessing and student blunder lower the $\mathrm{LK}_{\alpha<5 \%}$ values, because these combined effects shifted student marks higher, without any increase in knowledge.

\begin{tabular}{|c|c|c|c|c|c|c|c|c|c|}
\hline & \multicolumn{3}{|c|}{3 Choices/Question } & \multicolumn{3}{|c|}{4 Choices/Question } & \multicolumn{3}{|c|}{5 Choices/Question } \\
\hline \#Questions & $50 \%$ & $60 \%$ & $70 \%$ & $50 \%$ & $60 \%$ & $70 \%$ & $50 \%$ & $60 \%$ & $70 \%$ \\
\hline 2 & $-1-$ & $-1-$ & $-1-$ & $-1-$ & $-1-$ & $-1-$ & $-1-$ & $0 /-$ & $0 /-$ \\
\hline 4 & $-1-$ & $-1-$ & $-1-$ & $-1-$ & $-1-$ & $-1-$ & $-1-$ & $0 /-$ & $0 /-$ \\
\hline 6 & $-1-$ & $-1-$ & $1 / 0$ & $-1-$ & $0 /-$ & $1 / 0$ & $-1-$ & $0 /-$ & $2 / 1$ \\
\hline 8 & $-1-$ & $-1-$ & $1 /-$ & $-1-$ & $0 /-$ & $2 / 0$ & $-1-$ & $1 /-$ & $2 / 1$ \\
\hline 10 & $-1-$ & $-1-$ & $1 /-$ & $-1-$ & $1 /-$ & $2 / 0$ & $0 /-$ & $1 /-$ & $3 / 1$ \\
\hline 12 & $-1-$ & $1 /-$ & $3 / 1$ & $-1-$ & $3 / 0$ & $4 / 2$ & $0 /-$ & $3 / 1$ & $5 / 3$ \\
\hline 14 & $-1-$ & $1 /-$ & $3 / 1$ & $0 /-$ & $3 / 0$ & $5 / 2$ & $1 /-$ & $4 / 1$ & $5 / 3$ \\
\hline 16 & $-1-$ & $1 /-$ & $5 / 3$ & $0 /-$ & $3 / 1$ & $7 / 5$ & $2 /-$ & $4 / 2$ & $7 / 5$ \\
\hline 18 & $-1-$ & $2 /-$ & $5 / 3$ & $1 /-$ & $4 / 1$ & $7 / 5$ & $2 /-$ & $5 / 2$ & $8 / 6$ \\
\hline 20 & $-1-$ & $2 /-$ & $5 / 3$ & $1 /-$ & $4 / 1$ & $7 / 5$ & $3 /-$ & $6 / 2$ & $8 / 6$ \\
\hline 30 & $0 /-$ & $5 / 1$ & $10 / 7$ & $4 /-$ & $8 / 4$ & $13 / 10$ & $6 / 1$ & $10 / 6$ & $14 / 11$ \\
\hline 40 & $1 /-$ & $8 / 3$ & $15 / 11$ & $7 /-$ & $12 / 7$ & $18 / 15$ & $9 / 2$ & $15 / 9$ & $20 / 16$ \\
\hline 50 & $3 /-$ & $11 / 5$ & $20 / 16$ & $9 / 1$ & $17 / 10$ & $24 / 20$ & $12 / 5$ & $19 / 13$ & $26 / 22$ \\
\hline 60 & $5 /-$ & $15 / 8$ & $25 / 20$ & $12 / 3$ & $21 / 14$ & $29 / 25$ & $16 / 7$ & $24 / 17$ & $32 / 27$ \\
\hline 70 & $7 /-$ & $18 / 11$ & $30 / 25$ & $15 / 4$ & $25 / 17$ & $35 / 30$ & $19 / 9$ & $28 / 21$ & $38 / 33$ \\
\hline 80 & $9 /-$ & $22 / 13$ & $35 / 30$ & $18 / 6$ & $29 / 20$ & $41 / 35$ & $22 / 11$ & $33 / 25$ & $44 / 38$ \\
\hline 90 & $11 /-$ & $25 / 16$ & $40 / 34$ & $21 / 8$ & $34 / 24$ & $46 / 40$ & $26 / 13$ & $38 / 29$ & $50 / 44$ \\
\hline 100 & $13 /-$ & $29 / 19$ & $45 / 39$ & $24 / 9$ & $38 / 27$ & $52 / 45$ & $29 / 16$ & $42 / 32$ & $56 / 49$ \\
\hline 120 & $17 / 1$ & $36 / 25$ & $55 / 49$ & $30 / 13$ & $47 / 34$ & $64 / 56$ & $36 / 20$ & $52 / 40$ & $68 / 61$ \\
\hline 140 & $21 / 3$ & $43 / 30$ & $66 / 58$ & $36 / 16$ & $55 / 42$ & $75 / 67$ & $43 / 25$ & $61 / 48$ & $80 / 72$ \\
\hline 160 & $25 / 5$ & $50 / 36$ & $76 / 68$ & $42 / 20$ & $64 / 49$ & $87 / 77$ & $50 / 30$ & $71 / 57$ & $92 / 83$ \\
\hline 180 & $29 / 7$ & $58 / 42$ & $86 / 78$ & $48 / 24$ & $73 / 56$ & $98 / 88$ & $57 / 35$ & $81 / 65$ & $104 / 95$ \\
\hline 200 & $34 / 9$ & $65 / 48$ & $97 / 88$ & $54 / 28$ & $82 / 63$ & \begin{tabular}{|l|}
$110 / 99$ \\
\end{tabular} & $64 / 40$ & $90 / 73$ & $116 / 106$ \\
\hline 220 & $38 / 11$ & $73 / 54$ & $107 / 97$ & $60 / 31$ & $91 / 71$ & $121 / 110$ & $71 / 45$ & $100 / 81$ & $128 / 117$ \\
\hline 240 & $42 / 12$ & $80 / \mathbf{6 0}$ & $118 / 107$ & $66 / 36$ & $99 / 78$ & $133 / 121$ & $78 / \mathbf{5 0}$ & \begin{tabular}{|l|}
$109 / 89$ \\
\end{tabular} & $141 / 129$ \\
\hline 260 & $47 / 15$ & $87 / 66$ & $\mathbf{1 2 8} / 117$ & $72 / 40$ & $108 / 85$ & 144 / 132 & $85 / 54$ & $119 / 97$ & $153 / 140$ \\
\hline 280 & $51 / 17$ & $94 / 72$ & $\mathbf{1 3 9} / 127$ & $78 / 44$ & $117 / 92$ & $156 / 142$ & $92 / 59$ & $129 / \mathbf{1 0 6}$ & $165 / 152$ \\
\hline 300 & $56 / 19$ & 102 / 80 & $\mathbf{1 5 0} / 137$ & 84 / 47 & $126 / 101$ & $168 / 153$ & $99 / 65$ & $139 / 114$ & $177 / 163$ \\
\hline
\end{tabular}


Table 5. Pass marks required to detect 50\% and 60\% knowledge for various multiple choice question test structures, with $\leq 5 \%$ of a false positive. Values were computed from binomial distributions (Equation 3 ) or Monte Carlo simulations (boldface text) when limits of 64-bit computer arithmetic were reached. Table values are presented as ( $\beta=0 \%$, no educated guessing / $\beta=5 \%$, with educated guessing). Educated guessing and student blunder raise the required pass marks, because these combined effects require higher standards to compensate for those attained due to guessing.

\begin{tabular}{|c|c|c|c|c|c|c|}
\hline & \multicolumn{2}{|c|}{3 Choices/Question } & \multicolumn{2}{|c|}{4 Choices/Question } & \multicolumn{2}{|c|}{5 Choices/Question } \\
\hline $\begin{array}{l}\text { Knowledge } \\
\text { \#Questions }\end{array}$ & $\mathbf{5 0 \%}$ & $60 \%$ & $\mathbf{5 0 \%}$ & $60 \%$ & $\mathbf{5 0 \%}$ & $60 \%$ \\
\hline 2 & $-1-$ & $-1-$ & $-1-$ & $-1-$ & $-1-$ & $-1-$ \\
\hline 4 & $-1-$ & $-1-$ & $-1-$ & $-1-$ & $100.0 \% /-$ & $-1-$ \\
\hline 6 & $100.0 \% /-$ & $-1-$ & $\begin{array}{l}100.0 \% / \\
100.0 \% \\
\end{array}$ & $-1-$ & $\begin{array}{l}100.0 \% \text { I } \\
100.0 \% \\
\end{array}$ & $100.0 \% /-$ \\
\hline 8 & $\begin{array}{c}100.0 \% / \\
100.0 \%\end{array}$ & $100.0 \% /-$ & $\begin{array}{l}100.0 \% / \\
100.0 \%\end{array}$ & $\begin{array}{c}100.0 \% / \\
100.0 \%\end{array}$ & $\begin{array}{l}87.5 \% \text { I } \\
100.0 \% \\
\end{array}$ & $\begin{array}{c}100.0 \% \text { I } \\
100.0 \%\end{array}$ \\
\hline 10 & $\begin{array}{l}90.0 \% \text { / } \\
100.0 \%\end{array}$ & $\begin{array}{l}100.0 \% / \\
100.0 \%\end{array}$ & $\begin{array}{l}90.0 \% \text { I } \\
90.0 \%\end{array}$ & $\begin{array}{l}100.0 \% / \\
100.0 \%\end{array}$ & $\begin{array}{l}90.0 \% \text { I } \\
90.0 \%\end{array}$ & $\begin{array}{l}90.0 \% \text { I } \\
100.0 \%\end{array}$ \\
\hline 12 & $\begin{array}{l}91.7 \% \text { / } \\
91.7 \% \\
\end{array}$ & $\begin{array}{c}100.0 \% / \\
100.0 \% \\
\end{array}$ & $\begin{array}{l}83.3 \% \text { I } \\
91.7 \% \\
\end{array}$ & $\begin{array}{l}100.0 \% / \\
100.0 \% \\
\end{array}$ & $\begin{array}{l}83.3 \% \text { I } \\
91.7 \% \\
\end{array}$ & $\begin{array}{l}91.7 \% / \\
100.0 \% \\
\end{array}$ \\
\hline 14 & $\begin{array}{l}85.7 \% \text { I } \\
92.9 \%\end{array}$ & $\begin{array}{l}92.9 \% \text { / } \\
100.0 \%\end{array}$ & $\begin{array}{l}85.7 \% \text { I } \\
85.7 \%\end{array}$ & $\begin{array}{l}92.9 \% \text { I } \\
92.9 \%\end{array}$ & $\begin{array}{l}78.6 \% \text { I } \\
85.7 \%\end{array}$ & $\begin{array}{l}92.9 \% \text { I } \\
92.9 \%\end{array}$ \\
\hline 16 & $\begin{array}{l}87.5 \% / \\
87.5 \% \\
\end{array}$ & $\begin{array}{l}93.8 \% / \\
93.8 \% \\
\end{array}$ & $\begin{array}{l}81.3 \% \text { I } \\
87.5 \% \\
\end{array}$ & $\begin{array}{l}87.5 \% \text { I } \\
93.8 \% \\
\end{array}$ & $\begin{array}{l}81.3 \% \text { I } \\
87.5 \% \\
\end{array}$ & $\begin{array}{l}87.5 \% / \\
93.8 \% \\
\end{array}$ \\
\hline 18 & $\begin{array}{l}83.3 \% \text { I } \\
88.9 \% \\
\end{array}$ & $\begin{array}{l}88.9 \% \text { I } \\
94.4 \% \\
\end{array}$ & $\begin{array}{l}77.8 \% \text { I } \\
83.3 \% \\
\end{array}$ & $\begin{array}{c}88.9 \% \text { I } \\
88.9 \% \\
\end{array}$ & $\begin{array}{l}77.8 \% \text { I } \\
83.3 \% \\
\end{array}$ & $\begin{array}{l}83.3 \% \text { I } \\
88.9 \% \\
\end{array}$ \\
\hline 20 & $\begin{array}{l}85.0 \% \text { I } \\
85.0 \%\end{array}$ & $\begin{array}{l}90.0 \% \text { I } \\
90.0 \%\end{array}$ & $\begin{array}{l}80.0 \% \text { I } \\
85.0 \%\end{array}$ & $\begin{array}{l}85.0 \% \text { I } \\
90.0 \%\end{array}$ & $\begin{array}{l}75.0 \% \text { I } \\
80.0 \%\end{array}$ & $\begin{array}{l}85.0 \% / \\
85.0 \%\end{array}$ \\
\hline 30 & $\begin{array}{l}80.0 \% / \\
83.3 \% \\
\end{array}$ & $\begin{array}{l}86.7 \% / \\
86.7 \% \\
\end{array}$ & $\begin{array}{l}76.7 \% \text { I } \\
80.0 \% \\
\end{array}$ & $\begin{array}{l}83.3 \% \text { I } \\
86.7 \% \\
\end{array}$ & $\begin{array}{l}73.3 \% \text { I } \\
76.7 \% \\
\end{array}$ & $\begin{array}{l}80.0 \% / \\
83.3 \% \\
\end{array}$ \\
\hline 40 & $\begin{array}{l}77.5 \% / \\
80.0 \%\end{array}$ & $\begin{array}{l}82.5 \% / \\
85.0 \%\end{array}$ & $\begin{array}{l}72.5 \% \text { I } \\
77.5 \%\end{array}$ & $\begin{array}{l}80.0 \% \text { I } \\
82.5 \%\end{array}$ & $\begin{array}{l}70.0 \% \text { I } \\
75.0 \%\end{array}$ & $\begin{array}{l}77.5 \% \text { I } \\
80.0 \%\end{array}$ \\
\hline 50 & $\begin{array}{l}76.0 \% \text { I } \\
80.0 \% \\
\end{array}$ & $\begin{array}{l}82.0 \% \text { / } \\
84.0 \% \\
\end{array}$ & $\begin{array}{l}72.0 \% \text { I } \\
76.0 \% \\
\end{array}$ & $\begin{array}{l}78.0 \% \text { I } \\
82.0 \% \\
\end{array}$ & $\begin{array}{l}68.0 \% \text { I } \\
74.0 \% \\
\end{array}$ & $\begin{array}{l}76.0 \% / \\
80.0 \% \\
\end{array}$ \\
\hline 60 & $\begin{array}{l}75.0 \% \text { I } \\
78.3 \% \\
\end{array}$ & $\begin{array}{l}81.7 \% / \\
83.3 \% \\
\end{array}$ & $\begin{array}{l}71.7 \% \text { I } \\
75.0 \% \\
\end{array}$ & $\begin{array}{l}78.3 \% \text { I } \\
80.0 \% \\
\end{array}$ & $\begin{array}{l}68.3 \% \text { I } \\
73.3 \% \\
\end{array}$ & $\begin{array}{l}75.0 \% \text { I } \\
78.3 \% \\
\end{array}$ \\
\hline 70 & $\begin{array}{l}74.3 \% \text { I } \\
77.1 \% \\
\end{array}$ & $\begin{array}{l}81.4 \% / \\
81.4 \% \\
\end{array}$ & $\begin{array}{l}70.0 \% \text { I } \\
74.3 \% \\
\end{array}$ & $\begin{array}{l}77.1 \% \text { I } \\
80.0 \% \\
\end{array}$ & $\begin{array}{l}67.1 \% / \\
72.9 \%\end{array}$ & $\begin{array}{l}74.3 \% / \\
78.6 \% \\
\end{array}$ \\
\hline 80 & $\begin{array}{c}73.8 \% / \\
76.3 \% \\
\end{array}$ & $\begin{array}{c}80.0 \% / \\
81.3 \% \\
\end{array}$ & $\begin{array}{c}70.0 \% \text { I } \\
73.8 \% \\
\end{array}$ & $\begin{array}{c}76.3 \% \text { I } \\
78.8 \% \\
\end{array}$ & $\begin{array}{c}66.3 \% / \\
71.3 \% \\
\end{array}$ & $\begin{array}{c}73.8 \% \text { I } \\
77.5 \% \\
\end{array}$ \\
\hline 90 & $\begin{array}{l}73.3 \% \text { I } \\
75.6 \%\end{array}$ & $\begin{array}{l}80.0 \% / \\
81.1 \%\end{array}$ & $\begin{array}{c}68.9 \% \text { I } \\
73.3 \%\end{array}$ & $\begin{array}{l}75.6 \% \text { I } \\
78.9 \%\end{array}$ & $\begin{array}{l}66.7 \% \text { I } \\
71.1 \%\end{array}$ & $\begin{array}{l}73.3 \% \text { I } \\
76.7 \%\end{array}$ \\
\hline 100 & $\begin{array}{l}73.0 \% \text { I } \\
76.0 \% \\
\end{array}$ & $\begin{array}{l}79.0 \% \text { I } \\
80.0 \%\end{array}$ & $\begin{array}{c}69.0 \% \text { I } \\
73.0 \% \\
\end{array}$ & $\begin{array}{c}76.0 \% \text { I } \\
78.0 \% \\
\end{array}$ & $\begin{array}{l}66.0 \% \text { I } \\
71.0 \% \\
\end{array}$ & $\begin{array}{l}73.0 \% \text { I } \\
76.0 \% \\
\end{array}$ \\
\hline 120 & $\begin{array}{l}72.5 \% \text { / } \\
75.0 \%\end{array}$ & $\begin{array}{l}78.3 \% / \\
80.0 \%\end{array}$ & $\begin{array}{c}68.3 \% / \\
71.7 \% \\
\end{array}$ & $\begin{array}{c}75.0 \% \text { I } \\
77.5 \% \\
\end{array}$ & $\begin{array}{l}65.0 \% \text { I } \\
70.0 \%\end{array}$ & $\begin{array}{l}72.5 \% \text { I } \\
75.8 \%\end{array}$ \\
\hline 140 & $\begin{array}{c}72.1 \% \text { / } \\
74.3 \%\end{array}$ & $\begin{array}{l}78.6 \% \text { I } \\
79.3 \% \\
\end{array}$ & $\begin{array}{c}67.9 \% \text { I } \\
71.4 \% \\
\end{array}$ & $\begin{array}{c}74.3 \% \text { I } \\
77.1 \% \\
\end{array}$ & $\begin{array}{c}65.0 \% \text { I } \\
69.3 \% \\
\end{array}$ & $\begin{array}{l}72.1 \% \text { I } \\
75.0 \%\end{array}$ \\
\hline 160 & $71.9 \% /$ & $78.1 \% /$ & $66.9 \% /$ & $74.4 \% /$ & $64.4 \% /$ & $71.9 \% /$ \\
\hline
\end{tabular}




\begin{tabular}{|c|c|c|c|c|c|c|}
\hline & \multicolumn{2}{|c|}{ 3 Choices/Question } & \multicolumn{2}{c|}{ 4 Choices/Question } & \multicolumn{2}{c|}{ 5 Choices/Question } \\
\hline & $73.8 \%$ & $78.8 \%$ & $71.3 \%$ & $76.9 \%$ & $68.8 \%$ & $75.0 \%$ \\
\hline & $71.1 \% /$ & $77.8 \% /$ & $66.7 \% /$ & $73.9 \% /$ & $63.9 \% /$ & $71.7 \% /$ \\
& $73.3 \%$ & $78.3 \%$ & $70.6 \%$ & $76.1 \%$ & $68.3 \%$ & $74.4 \%$ \\
\hline & $71.0 \% /$ & $77.5 \% /$ & $66.5 \% /$ & $73.5 \% /$ & $64.0 \% /$ & $71.5 \% /$ \\
200 & $73.5 \%$ & $78.5 \%$ & $70.5 \%$ & $76.0 \%$ & $68.5 \%$ & $74.5 \%$ \\
\hline & $70.9 \% /$ & $77.3 \% /$ & $66.4 \% /$ & $73.6 \% /$ & $63.6 \% /$ & $71.4 \% /$ \\
220 & $73.2 \%$ & $78.2 \%$ & $70.0 \%$ & $75.9 \%$ & $68.2 \%$ & $74.1 \%$ \\
\hline & $70.8 \% /$ & $77.1 \% /$ & $66.3 \% /$ & $73.3 \% /$ & $63.3 \% /$ & $71.3 \% /$ \\
240 & $72.9 \%$ & $77.9 \%$ & $70.0 \%$ & $75.4 \%$ & $67.9 \%$ & $73.8 \%$ \\
\hline & $70.4 \% /$ & $76.9 \% /$ & $66.2 \% /$ & $73.1 \% /$ & $63.5 \% /$ & $71.2 \% /$ \\
260 & $72.7 \%$ & $77.7 \%$ & $69.6 \%$ & $75.4 \%$ & $67.7 \%$ & $73.8 \%$ \\
\hline & $70.4 \% /$ & $76.8 \% /$ & $66.1 \% /$ & $73.2 \% /$ & $63.2 \% /$ & $71.1 \% /$ \\
280 & $72.5 \%$ & $77.5 \%$ & $69.6 \%$ & $75.4 \%$ & $67.5 \%$ & $73.6 \%$ \\
\hline & $70.3 \% /$ & $\mathbf{7 6 . 3 \%} /$ & $65.7 \% /$ & $\mathbf{7 2 . 7 \%} /$ & $63.0 \% /$ & $\mathbf{7 0 . 7 \% /}$ \\
& $72.3 \%$ & $\mathbf{7 7 . 3 \%}$ & $69.3 \%$ & $\mathbf{7 5 . 3 \%}$ & $67.3 \%$ & $\mathbf{7 3 . 3 \%}$ \\
\hline
\end{tabular}


Table 6. Summary of the Independent Effects of Multiple Choice Question Test Design Structural Elements

\begin{tabular}{|l|c|c|}
\hline MCQ Test Design Structure & $\begin{array}{c}\text { Effect on } \\
\text { LK }_{\alpha<5 \%}\end{array}$ & $\begin{array}{c}\text { Effect on } \\
\text { Required Pass } \\
\text { Mark }\end{array}$ \\
\hline Increasing \# questions & $\uparrow$ & $\downarrow$ \\
\hline Increasing \# choices/question & $\uparrow$ & $\downarrow$ \\
\hline Educated guessing & $\downarrow$ & $\uparrow$ \\
\hline Student blunder & $\uparrow$ & $\downarrow$ \\
\hline Educated guessing + 5\% Student Blunder & $\downarrow$ & $\leftrightarrow / \uparrow$ \\
\hline
\end{tabular}

*Level of knowledge at a Type I error rate of 5\% 